\title{
El habla como expresión de la cultura popular*
}

\author{
Speech as an expression of popular culture
}

\author{
Yineth Riaño Bayona, M.Sc. \\ Universidad Distrital Francisco José de Caldas \\ E-mail: yinethriao@yahoo.es
}

Received 19-Jun-2013/Accepted 22-Oct-201

Resumen

Este artículo presenta resultados de una investigación cualitativa con jóvenes de la ciudad de Bogotá, Colombia, cuyo objetivo fue comprender las representaciones sociales implícitas en sus expresiones cotidianas y cómo estas expresiones construyen y transforman la cultura popular con base en la aplicación de encuestas y la producción de textos escritos. El trabajo se enmarca en una perspectiva lingüística y sociológica y se realizó con cien estudiantes de un colegio de Bogotá cuyas edades oscilaban entre los 14 y 17 años de edad. Los resultados de la investigación mostraron que las representaciones sociales de los jóvenes bogotanos, presentes en sus expresiones cotidianas, tienen que ver con valores preestablecidos socialmente, con formas utilizadas para configurar su identidad como individuos y como miembros pertenecientes a algún grupo social y, con las ideas acerca de cómo comportarse o relacionarse con otros. La cultura popular, con la oposición de los jóvenes a lo establecido, manifiesta a través del uso informal del lenguaje y la creación de palabras carentes de los requisitos necesarios para ser consideradas como propias de la cultura superior. En este sentido, se constató la mediación de la cultura superior en la existencia de la cultura popular.

Palabras claves: cultura popular, habla, lenguaje, representaciones sociales.

\section{Abstract}

This article represents the outcomes of a qualitative research applied to teenagers from the city of Bogota, Colombia. The objective of this research is to understand the social representations implicit in their everyday expressions, and how these representations construct and transform popular culture, based on survey application and production of written texts. This work is developed from a linguistic and sociological perspective, and was performed with one hundred students from a school in Bogota, whose ages ranged between 14 and 17 years. The results of this research have shown that the social representations of teenagers in Bogota, which are common in their daily expressions, are concerned with social presets, the ways they use to set their identity as individuals belonging to a specific social group, and also with the ideas they have about how to behave and interact with others. Popular culture with youth opposition to the established, is manifested through the informal use of language and the creation of words without the necessary requirements to be considered as belonging to the high culture. In this sense, mediation of this high culture was found in the existence of popular culture.

Key words: popular culture, speech, language, social representations.

\section{Résumé}

Cet article présente une partie des résultats d'une recherche qualitative faite avec des jeunes qui habitent à Bogota, Colombie, et son but était d'essayer de comprendre les représentations sociales implicites dans ces expressions quotidiennes et de comprendre de quelle façon ces expressions construisent et transforment la culture populaire. La recherche s'appuie sur l'application d'enquêtes et la production de textes. Cette recherche a était élaboré dans une école à Bogota avec des élèves âgés entre 14 et 17 ans. Elle se fonde sur une perspective linguistique et sociologique. Les résultats de la recherche ont montré que les représentations sociales des jeunes de Bogotá, présentes dans leurs expressions quotidiennes, sont liées à des valeurs préétablis par la société ou la communauté dont ils font partie, à partir des formes qui préfigurent leur identité en tant qu'individus faisant partie d'un groupe de personnes, et à partir de leurs façons de se

* Este artículo está asociado a la investigación Representaciones en el habla de la juventud bogotana: una expresión lexicográfica de la cultura popular, realizada como requisito para obtener el título de Magíster en Investigación Social Interdisciplinaria. 
conduire et de se mettre en rapport avec les autres. La culture populaire, qui comporte la tendance des jeunes de s'opposer aux normes établies, se manifeste à partir de l'utilisation d'un langage informel et de la création d'un vocabulaire qui ne compte pas avec les prérequis nécessaires pour faire partie de la culture supérieur. De cette façon il était possible de constater la médiation de la culture supérieure dans la formation de la culture populaire.

Mots clés: culture populaire, discours, langue, représentations sociales.

\section{Introducción}

Este texto señala el papel que cumplen las expresiones de los jóvenes bogotanos en la construcción, modificación y reproducción de la cultura popular, a partir del acercamiento a las representaciones sociales que subyacen a éstas. La importancia de estudiar las representaciones sociales de los jóvenes, se centra en comprender los significados de sus expresiones cotidianas y, en cómo estas representaciones orientan sus formas de concebir el mundo, comportarse, relacionarse $\mathrm{y} / \mathrm{o}$ valorar las acciones propias o ajenas, puesto que, de acuerdo con Fernández (2002), la cultura popular como una realidad viva, dinámica y actual, en la cual todas las personas, de forma consciente o no y en algún momento y grado, participan", permite entrever su fundamentación en representaciones sociales. En palabras de Canclini (1989), la cultura popular se trata más de una construcción ideológica que está por encontrar su consistencia teórica. De ahí que, en este trabajo la cultura popular se haya asumido como un espacio simbólico en el cual confluyen diversidad de textos, lenguajes, prácticas discursivas, e, incluso, aquello que Bajtin (1997) considera como propio de la cultura alta o superior $y$, las representaciones sociales, de acuerdo con Abric (1994), como acciones sobre la realidad, que preceden y determinan las interacciones.

Esta investigación se realizó con el propósito de establecer las representaciones sociales que subyacen a las diversas formas de expresión de los jóvenes bogotanos, asociadas con sus formas de relación como individuos pertenecientes a un grupo social, su forma de valorar el comportamiento de otros y los mecanismos utilizados para expresar realidades, inconformidades o recrear situaciones cotidianas, producto de la sociedad a la cual hacen parte, en razón del papel que el lenguaje tiene en la construcción de la cultura, y, a su vez, el papel que la cultura juega en la transformación del lenguaje.

Como parte de los antecedentes se estudió la investigación de José Joaquín Montes (1998), centrada en considerar las diferencias fonéticas, gramaticales y lexicales de los hablantes bogotanos en relación con su estratificación social. También la teoría de Bajtin (1997) expuesta en La palabra en la vida y la palabra en la poesía, acerca de la palabra como un producto ideológico de la sociedad en la cual emerge, a la vez que como una construcción de modos particulares de relación entre creadores y receptores cuando afirma que todos los elementos que rodean nuestro mundo material o "realidad" existen gracias a la posibilidad que tenemos de representarlos o nombrarlos mediante las palabras. Bajtin señala cómo la palabra, al hallarse determinada por los acontecimientos de la vida, se convierte en una unidad indisoluble que se expresa en los juicios o valoraciones sobre las situaciones de la vida de una sociedad o cultura particular.

Dentro de los referentes teóricos que fundamentaron el estudio, se encuentran los presupuestos de Bajtin sobre cultura popular y los presupuestos de Burke sobre lengua, cultura y poder, desde una perspectiva lingüística y sociológica. La teoría de Bajtin construida con base en el texto de Rabelais , define la cultura popular como transgresiva e integrada por distintas prácticas discursivas y no discursivas (Zubieta, et al, 2000). Lo no discursivo hace referencia a aquellos comportamientos que son nombrados con el discurso, y a los elementos de carácter simbólico que exponen la influencia recíproca o, la confluencia de elementos populares y oficiales. 
Por otra parte, se tomaron en consideración los presupuestos teóricos de Burke según los cuales el estudio de la lengua y el lugar que ésta ocupa en la cultura, señala una relación estrecha con el poder del lenguaje y con la relación existente entre el lenguaje y otras formas de poder. Algunos de los tópicos principales en el estudio de la lengua, referidos por Burke, son las variaciones que se presentan en el uso de la lengua por parte de los mismos individuos, el hecho que la lengua refleje la sociedad o la cultura en la que se usa y, recíprocamente, el hecho que la lengua moldee la sociedad en la que se usa. Citando a Meillet, Burke (1993) señala que "las lenguas sirven para expresar la mentalidad de quienes las hablan, pero cada lengua constituye un sistema en alto grado organizado que se impone a los hablantes y da forma a sus pensamientos" (p. 15). Por consiguiente, en el caso de los insultos, lo que se expresa es una transgresión de las reglas y de las convenciones sociales estereotipadas o "ritualizadas", tal como propone Burke (1993) en su historia social del lenguaje.

\section{Perspectivas teóricas}

\section{Cultura popular}

El estudio de la cultura popular se realizó desde la perspectiva planteada por Bajtin (Citado por Zubieta, et. al., 2000), según la cual, este concepto abarca una serie de significados que se asocian por un lado, a la cultura popular, como milenaria, propia de la plaza pública, del humor popular y del cuerpo; y, por otro, a la cultura oficial, cuyo carácter se define por lo serio, lo religioso y lo feudal. Para Bajtin, según (Zubieta, et al., 2000), la cultura popular aparece como no religiosa, exterior a la cultura dominante de la iglesia $y$, a su forma de ordenar el mundo, y, desarrollada en el ámbito de la fiesta en la plaza pública y erigida sobre una lógica cuyos valores, jerarquías, normas y tabús religiosos, políticos y morales se instauran en oposición al dogmatismo y la "seriedad" propia de la cultura oficial. Por esta razón, Bajtin propone una circulación entre la cultura oficial y la cultura popular, en la cual opera por un lado, una captura simbólica (imaginaria) sobre el letrado para irrumpir en la cultura oficial, y, por otro lado, las jerarquías, los valores y los ritos de la cultura oficial que, mediante el mecanismo de la inversión y la ridiculización grotesca, entran en la cultura popular a la que denomina como "baja" cultura (Zubieta et al., 2000, p. 30)

¿Qué son las representaciones sociales? ¿Cómo se construyen?

Según lo expuesto por Abric (1994), las representaciones sociales se entienden "como una visión funcional del mundo que permite al individuo o al grupo conferir sentido a sus conductas, y entender la realidad mediante su propio sistema de referencias y adaptar y definir de este modo un lugar para sî" (p. 13). Desde esta perspectiva, la forma en que los jóvenes bogotanos se refieren al mundo que los rodea, su forma de comportarse y su forma de valorar los comportamientos de otros, se halla predeterminada por un sistema de valores construidos social e históricamente. En este sentido, las representaciones sociales constituyen un mecanismo utilizado por los jóvenes bogotanos para configurar su identidad como individuos y como miembros pertenecientes a un grupo social, al encontrar referentes objetivos sobre la realidad ${ }^{1}$, los cuales les indican como comportarse y relacionarse socialmente.

Es de anotar, de acuerdo con lo expuesto por Abric (1994), que estas representaciones sociales de los jóvenes bogotanos están mediadas por un sistema cognitivo, el cual no sólo les permite reconstruir la realidad, sino también asignarle una significación particular acorde con factores circunstanciales como las situaciones en las cuales participan, la finalidad de estas situaciones, su condición social, su historia individual o grupal y, los desafíos sociales, entre otros. Por consiguiente, en este trabajo las representaciones sociales se asumieron como una forma para explicar la significación que los jóvenes hacen acerca de la realidad.

1. El texto al que se hace referencia es Gargantúa y Pantagruel una novela que surgió en el contexto de la Edad Media y el Renacimiento. 


\section{Funciones de las representaciones sociales}

Algunas de las representaciones sociales sobre las cuales se configuran las conductas humanas y se construye el tejido social, son la función de saber, la función de orientación y la función identitaria, tal como lo plantea Abric (1994):

La función de saber que cumplen las representaciones sociales, se establece como la condición necesaria para la existencia de la comunicación en una sociedad, al definir un marco de referencia común, transmitir y difundir el saber "ingenuo" ó "sentido común", en términos de Moscovici (citado por Abric, 1994, p.15). Por lo tanto, los conceptos que los jóvenes bogotanos asignan a su realidad circundante, se basan en valores y conocimientos aprehendidos social y culturalmente, los cuales expresan formas de entender, nominar y explicar la realidad.

La función de orientación de las representaciones sociales, se entiende como un sistema de precodificación de la realidad, una guía para la acción, una forma de actuar sobre la realidad y, un modo de determinar el comportamiento de los individuos (Abric, 1994) Es decir que, la representación define la finalidad de las situaciones en las que participan los jóvenes bogotanos y otros elementos de la representación de las situaciones como: la representación de sí mismos, de un grupo o de otros.

La función identitaria se entiende como la ubicación de los individuos y los grupos en el campo social, haciendo posible la elaboración de una identidad social y personal, compatible con los sistemas de normas y valores que han sido determinados social e históricamente, según lo exponen, Mugny y Carugati, citados por Abric (1985) Además del control social de una colectividad sobre cada uno de miembros, principalmente, en los procesos de socialización. La función identitaria de las representaciones sociales posibilita entonces reconocer, como ya se señaló anteriormente, la forma en que los jóvenes bogotanos valoran a otros de acuerdo con un sistema de normas y valores determinados social e históricamente, así como, los mecanismos de control social que un grupo ejerce sobre cada uno de sus miembros.

Entre tanto, Abric (1994) considera que las representaciones sociales involucran una dimensión funcional referida a la capacidad que tienen los sujetos para incorporar conocimientos en la creación de expresiones identitarias y en el establecimiento de relaciones sociales y, una dimensión normativa referida a la determinación que el entorno social impone a los sujetos para expresarse y establecer relaciones con otros. Por lo tanto, el acercamiento a las representaciones sociales de los jóvenes bogotanos conlleva también a entender sus identidades y mecanismos de interacción social.

\section{Metodología}

Para la realización de este estudio se utilizó un enfoque cualitativo, tomando en consideración las expresiones utilizadas por los jóvenes bogotanos, en su cotidianeidad, para nombrar, agredir o calificar a familiares, compañeros o amigos, designar actividades, expresar circunstancias como sentirse bien, estar triste, aburrido, fastidiado, etc, nombrar objetos o acciones y calificar situaciones con la finalidad de identificar el uso de estas palabras en contexto y el significado que le otorgan a cada una de ellas; además de la representación social a partir de la cual se configuran. Seguidamente, en el estudio se abordó la pregunta sobre cómo estas expresiones participan en la construcción de la cultura popular.

En la recolección de información se aplicaron dos instrumentos a cien estudiantes de educación media de un colegio de Bogotá cuyas edades oscilaban entre los 14 y 17 años de edad, y, se contó con la colaboración de los docentes de Lengua Castellana de educación media, quienes generaron un espacio para su desarrollo. El primer instrumento consistió en una encuesta, en la cual se indagaba por palabras, frases o dichos conocidos y utilizados por los jóvenes y por sus amigos en sus conversaciones cotidianas. El segundo instrumento fueron los textos escritos por los 
jóvenes participantes. Para lograr dicha producción se les solicitó escribir el mayor número de palabras utilizadas para nombrar a familiares, compañeros o amigos, designar actividades, agredir a sus familiares, compañeros o amigos, calificar a sus familiares, compañeros o amigos, expresar circunstancias como sentirse bien, estar triste, aburrido, fastidiado, etc., nombrar objetos o acciones y calificar situaciones.

Los instrumentos diseñados tuvieron como propósito recolectar expresiones utilizadas por los jóvenes bogotanos, al igual que el(los) significado(s) asignado(s) por éstos, para llegar a establecer qué función cumplen las representaciones sociales (saber, identidad u orientación), en la formación y reproducción de la cultura popular. Adicionalmente, se aplicaron con el fin de analizar la dimensión funcional (marca de la cultura) y la dimensión normativa (normas del entorno social) que denotan las expresiones utilizadas por los jóvenes bogotanos y dan significación a las representaciones sociales que las configuran.

\section{Sobre el procedimiento para el análi- sis de los datos}

Los instrumentos constituyeron una herramienta para identificar las representaciones sociales presentes en el habla de los jóvenes bogotanos y para analizar el papel que juegan las expresiones de los jóvenes bogotanos, en la configuración de la cultura popular. Inicialmente se plantearon las categorías con base en los referentes teóricos utilizados: la comprensión de las jerarquías, la inversión de los valores de la cultura oficial, los criterios éticos y estéticos y la subjetividad del hablante, subyacentes a las prácticas discursivas de los jóvenes, según lo expuesto por Bajtin (ver Tabla 1) y luego se clasificaron las palabras en relación con las representaciones sociales, junto a los significados asignados por los jóvenes (ver Anexo 1) La vinculación entre estas categorías se generó utilizando el corpus de palabras y textos escritos, en relación con los referentes teóricos utilizados en este estudio.
Tabla 1. Categorías e indicadores provenientes del análisis del habla juvenil bogotana.

\begin{tabular}{|c|c|}
\hline CATEGORÍA & INDICADORES \\
\hline Cultura popular & $\begin{array}{l}\text { Prácticas discursivas del sujeto relacio- } \\
\text { nadas con: } \\
\odot \text { Jerarquías } \\
\odot \text { Inversión de los valores de la cultura } \\
\text { oficial } \\
\odot \text { Criterios éticos y criterios estéticos } \\
\odot \text { La subjetividad del hablante }\end{array}$ \\
\hline
\end{tabular}

La selección de las palabras, en la encuesta, se realizó teniendo en cuenta aquellas palabras cuya recurrencia fue mayor. La selección de los textos, como producción escrita autónoma, se realizó teniendo en cuenta el léxico utilizado por los jóvenes y la incorporación de neologismos ${ }^{1}$. Se adoptó como metodología el AC (análisis de contenido) del corpus lexicográfico, recolectado a través de la lista de palabras y la producción textual de los jóvenes.

\section{Resultados y discusión de resultados}

El análisis de la información recolectada en las encuestas y la producción de textos escritos por parte de los jóvenes participantes, permitió comprender las representaciones sociales presentes en sus expresiones cotidianas y cómo éstas construyen y transforman la cultura popular. Las categorías que se establecieron para el análisis de contenido fueron representaciones sociales y cultura popular. Las representaciones sociales relacionadas con la función saber, la función identidad, la función orientación y criterios éticos y estéticos y, la cultura popular relacionada con jerarquías, tal como se relaciona en los anexos.

Al ser el lenguaje una fuente ineludible de la cultura, las expresiones chirri (ñero), pifi (poca cosa), Roberto (mujer parecida a un hombre), burro (hombre moreno y narizón), pelota (tonto, bobo), chirreto (ordinario), garbimba (ordinario), gremlin (enano),

1 Es decir, la asignación de significados idénticos a nuevas palabras o la sustitución de algunas palabras por otras como en el caso de la palabra balciar, utilizada para designar el verbo bailar. 
chichón de piso (enano), baboso (bruto), rata (ladrón), guiso (persona ordinaria), petardo (estúpido), coica (mujer bruta), poncio (tarado, bobo), gil (lento), zarnoso (persona extraña), smigolom (persona fea que combina dos personajes de la película El Señor de los Anillos), guiza (mujer ordinaria), zunga (mujer fácil), foxxic (zorrita), coiro (tonto), boby (tonto) y cula (estúpida), indican relaciones jerárquicas que explican el comportamiento de un grupo de jóvenes frente a otros, al referirse a sus compañeros o amigos de forma despectiva, agredirlos, ridiculizarlos, mostrarlos como inferiores a ellos, o expresar cualidades estéticas (ver Anexo 2). En este sentido, es interesante observar como la consideración de unos jóvenes bogotanos a otros, como inferiores, admite representaciones sociales relacionadas con la concepción de sí mismos como mejores, más bellos o legitimados para criticarlos, las cuales están mediatizadas por sus concepciones culturales sobre las personas cumplidas, honestas, no ridículas, con status social, bellas, inteligentes, de apariencia física agradable, honestas, ágiles o normales.

De modo que estas expresiones también señalan la construcción de la cultura popular como un modo de marcar diferencia entre los sujetos que pertenecen a un mismo grupo y expresar su intención de invertir lo establecido, cucha (mujer mayor), parche (modo de designar el grupo de amigos) y Big Cola (asociación entre una marca de gaseosa y la cola grande de la profesora), como lo muestra el siguiente relato de una joven a una de sus amigas:

Oe July vea que en el cole hay una cucha y le dicen Big Cola y es re-fastidiosa y la jodian y no le dejaban hacer clase y fue un parche y nos volamos de clase a jugar palo

Instrumento No. 02: Producción de textos escritos (septiembre 05 de 2011)

De otro lado, las expresiones de los jóvenes bogotanos relacionadas con la inversión de los valores de la cultura oficial, se explica por algunas de sus expresiones como párese duro (pelee), píntemela (incitación a pelear), pisarse (irse), vemos (chao), pille (vea), oe! (venga), a lo bien (en serio), iqué culiado! (palabra utilizada para calificar a alguien como bruto), bestia (palabra utilizada en oposición a persona inteligente y estudiosa), chimba (bueno), iqué paila! (algo que está mal), pichipanguanorrea (incumplido, sin palabra), pirogorsofia (alzado, pasado de la raya), asaltacunas (pedófilo), piltrofia (el caga parches), burro (hombre moreno), brinco (robo), asare (estar asustado), parlar (hablar), ojete (trasero), parce (amigo), la mamá de los pollitos (persona que se cree mejor que los demás o engreída), pichurria (mala gente), las cuales admiten, por sí mismas, la emergencia de la cultura popular al expresar su oposición a lo establecido en el uso de un tono informal del lenguaje, el establecimiento de relaciones sinonímicas o asociativas entre las palabras para referir significados, usar groserías para tratar a otros, señalar relaciones entre situaciones o personajes convencionales y aquellas aprehendidas de otros contextos y, mostrar un distanciamiento en la creación de lenguajes carentes de los requisitos necesarios para ser considerados como propios de la cultura oficial. Esta es la razón por la cual el uso del lenguaje constituye un elemento diferenciador, entre grupos, que además revela la relación entre los jóvenes bogotanos como sujetos, y, su cultura, a la cual resignifican mediante ésta.

Entre tanto, la emergencia de la cultura con un carácter popular, tiene que ver con la confluencia de diversos elementos en un contexto particular como en el caso de las expresiones pichurria (mala gente), cachetoso (muy elegante, bueno), caleto (callado), calceto (faltón), perro (amigo), chirreto (chambón), garbimba (tonto, bobo), ñero (amigo), re-ñero (gamín), pex (parcero), gremlin (enano), chichón de piso (enano), mi chancla (amigo), en las cuales, los significados asociados a cada una, denotan aspectos relacionados con la personalidad, la estética y la amistad, desde representaciones sociales relacionadas con la emisión de juicios morales, a través de los cuales los jóvenes bogotanos califican positiva o negativamente 
a otros (ver Anexo 1) Unos elementos que permiten a la vez, definir y diferenciar a los usuarios -jóvenes- de estas expresiones de otros grupos sociales. En otras palabras, configurar un carácter identitario que revela elementos compartidos y diferenciadores de otros grupos, que resulta de la interacción de los jóvenes bogotanos con un entramado simbólico de tradiciones e ideas. Las representaciones sociales que señalan las expresiones descritas, anteriormente, tienen que ver con la forma en que unos sujetos valoran a otros de acuerdo con un sistema de normas y valores determinados social e históricamente, tales como la belleza, la amistad o la lealtad. Por consiguiente, revelan también un mecanismo para reconocerse como miembros pertenecientes a un grupo, al perpetuar el control social que un grupo ejerce sobre ellos.

En la siguiente producción escrita la joven expresa un juicio o valoración negativa acerca de la labor de los bomberos, al igual que la inversión de lo establecido al calificarlos en forma despectiva, como impedidos. Algunos juicios o valoraciones acerca de las mujeres que son víctimas del incendio son feas, gordas, guizas, re bolas e impedidas:

No pues tu vieras lo que me pasó el sábado pasado, eran prácticamente las tres de la mañana, yo estaba super dormida, y empiezo a escuchar como si nos estubieran robando osea se escuchaban como los vidrios se rompían, y me levante súper asustada, y veo que mary osea maria mi empleada bajaba rápidamente las escaleras, y era que la casa de al lado se estaba incendiando y yo como Wow (loca) no puedo creer que estoy viendo eso, la empleada fue a avisarle a mi mamá, porque mi mamá puede que se caiga el mundo y ni cuenta se da re sorda. Bueno el caso salimos de la casa a mirar, y ush esa casa parecía un infierno. Los vecinos trataron de abrir la puerta, pero la muy bruta de la dueña de esa casa la dejo como asegurada y claro eso tuvieron que romper los vidrios, pero nada así rompieron la puerta con un extintor y bueno todo el mundo llamando a los bomberos, y nada que llegaban, así que sacaron mi súper mangera y la de otro vecino y con muchos extintores. Aunque la verdad eso no sirvió de un carajo, si no fueran por las mangeras esa señora y la hija no se salvan. No estoy siendo ficty (exagerada) bueno aunque los vecinos fueron de gran ayuda. Bueno después de apagar ese incendio a la media hora llegaron los impedidos de los bomberos (imposibilitados), policía, ambulancia y sale esa vieja y la hija re negras súper carboneras, y las atiende la ambulancia y va esta señora la dueña de la casa y al rato se pone disque a fumar re loca, pero el hecho de que hubiera pasado esto fue bueno por que la vieja se largo del conjunto con la gorda de su hija por que las dos eran re feas, gordas, guizas y la mamá era una pocholera y se creían de lo mejor cuando las dos eran re bolas e impedidas (brutas e imposibilitadas)

Instrumento No. 02: Producción de textos escritos (septiembre 05 de 2011)

En la siguiente producción escrita se evidencia como el joven responde en forma grosera a la agresión proferida por su compañero, sin tener en cuenta convención social alguna. De modo que aquí la inversión de lo establecido se expresa en la forma de referirse al compañero, comportarse y describir la situación presentada:

Era un lunes de parce (amigos), todo iva bien cuando un chino marica (Moncayo) empezó a madrear a una amiga (Leidy), yo sulfurado empezé a putearlo diciéndole grocerias...etc... pero el con la escusa de un simple mal entendido me hecho un yogurth encima....hay se armó el bonche (pelea) y yo lo putié (insultar) y le devolví el pequeño incidente tirando el yogurth 
en todo el saco, luego me enrraboné

(enojarse) y me fui al salón

Instrumento No. 02: Producción de textos escritos (septiembre 05 de 2011)

Tanto en los textos anteriores como en la mayor parte de las expresiones recolectadas en este trabajo (ver Anexos 1 y 2), se evidencia un número significativo de voces insultantes y despectivas que caracterizan las relaciones de los jóvenes bogotanos con compañeros o amigos. Además, dan cuenta de representaciones sociales de los jóvenes bogotanos, asociadas a ideas como la belleza, la fidelidad, las personas de palabra, las personas atrevidas, las personas de condición social baja o las personas consideradas insignificantes. Otro de los aspectos que muestran una herencia socio-cultural de los valores y de los conocimientos; así como, la forma escogida por los jóvenes bogotanos para trasgredir las normas sociales e instaurar nuevos modos de significación social e individual.

Desde el punto de vista de los juicios o valoraciones positivas o negativas emitidas por los jóvenes bogotanos, se revelaron representaciones sociales relacionadas con criterios éticos y criterios estéticos como fundamento para calificar a las personas, o, las acciones que éstas realizan, en la creación de palabras o expresiones que les permiten concretar su modo de pensar, representar a otros, conservar y generar nuevos valores y realidades, tal como se expone en el (Anexo 1)

En otras palabras, el lenguaje expresa la cultura de los hablantes, en este caso, los jóvenes bogotanos y sus condiciones culturales o modos de resignificación. Además de su subjetividad, la cual tiene que ver con las formas particulares de sentir, asumir la realidad, actuar sobre ésta y generar sentidos, transgrediendo los valores existentes y buscando formas de visibilización individual y colectiva. En la siguiente producción escrita, la joven interviene en defensa de su compañera, aduciendo no haberla dejado morir y haberse parado duro para que no se metieran con ella; y, su amigo, en defensa de ella; unos compor- tamientos que muestran representaciones sociales sobre aquello que socialmente está establecido de antemano, se hace por los amigos. También, representaciones sociales identitarias que cumplen algunas palabras como curtido, visajió y todo copas, utilizadas por la joven para referir la experiencia con sus amigos:

\begin{abstract}
Una vez ratica "Cristian" tuvo una gran pelea con una nena por que la vieja decía que ratica había curtido (cansado) a chinche la nena visajió (poner en evidencia) a rata por facebook, así que casi todas las parseras de rata se metieron a bacilar a la vieja y como la gente que rodea a ratica es peligrosa querían darle piso a la nena pero como yo conocía a la nena no la deje morir y me pare dura pues para que no se metieran con ella como yo soy la socia de rata (amiga), él no dejo que ninguna vieja se metiera conmigo; las mandó a volar y con la nena quedó todo copas (expresión utilizada para referir un estado saludable)

Instrumento No. 02: Producción de textos escritos (septiembre 05 de 2011)
\end{abstract}

Por otra parte, el uso y el significado conferido a palabras y expresiones como lámpara, gay, marikón, le hicimos empanada en la maleta, por lámpara le paso es por sapo, se está volviendo re loca y, ya no es aspero ni bacano haora es un maricon lámpara, utilizadas por el joven bogotano en la siguiente producción escrita, aparecieron determinadas por la situación que lo genera y por la interacción entre sus participantes. Igualmente, expusieron la forma en la que las representaciones sociales definen la visión que los jóvenes tienen acerca de sí mismos o de otros. Por lo tanto, para los jóvenes bogotanos la definición de una situación como lícita o inaceptable, en un contexto social determinado, se halla determinada de antemano.

\section{El dia de lámpara}

aquel dia que el gay de juan dijo en el salón unos chistes Mas Malos, que 
todos terMinaMos pegándole hasta que llegó un profesor y nos dijo que nos iba a hacer seguimiento, desde hay nadie le habló al Marikon de juan por sapo por ir a decir que sieMpre le pegábamos y que el nunca nos hacia nada. Cuando salimos a descanso le hiciMos eMpanada en la Maleta, le dañamos los esferos y Cuando él llegó no sabia que hacer, por láMpara le paso es por sapo además se esta volviendo re loca y nada le gusta y ya no es áspero ni bacano haora es un Maricón láMpar.

Instrumento No. 02: Producción de textos escritos (septiembre 05 de 2011)

La nominación de la realidad por parte de los jóvenes bogotanos surge de la posibilidad que le otorgan las palabras. Por esta razón su forma particular de expresarse, constituye un modo de manifestar su subjetividad y sugerir un sentido particular a las palabras, como en el caso de las palabras parchar (salir o estar con los amigos), parcero (amigo), lukas (dinero), chapuzón (baño), chiros (ropa), rose (sinónimo de vuelta), piques (sinónimo de carrera) y cucha (modo de referirse a la mamá), incluidas en el siguiente texto:

Era un sábado por la mañana y tenia ganas de parchar con un Amigo y llame a Daniel mi mejor parcero, decidimos encontrarnos en el parque.

Yo estaba con mi parcero, a él y a mi le habían dado 5 mil lukas. Decidimos ir a los juegos mecánicos y después ir a darnos un chapuzón (baño) en el rio guardamos los chiros (ropa) en la tula que traia, despues de bañarnos mas o menos 2 horas, nos quedaban solo mil pesitos y fuimos a jugar Xbox, solo nos alcanzo para una hora.

A la salida nos encontramos con 2 parceros (amigos) y les pedimos que nos dieran un rose (vuelta) en las ciclas, despues de apostar piques (carreras) nos abrimos cada uno para su casa. Mi cucha (mamá) estaba enojada por demorarme tanto y yo me emputé y me fui a dormir.
El proximo dia nos conectamos por facebook y decidimos hacer lo mismo todos los sábados

Instrumento No. 02: Producción de textos escritos (septiembre 05 de 2011)

También, en las expresiones resaltadas en la siguiente producción escrita, se evidenció como el lenguaje utilizado por la joven, posibilita la caracterización del grupo social al que pertenece, su cohesión y el despliegue de su subjetividad, ya que el lenguaje constituye el principal elemento cultural para la representación de puntos de vista, sentimientos y vivencias, como en las expresiones guiso, falceto, asorarse, choro, garbimba, rata. Es decir, la expresión de significados a través de diversas formas simbólicas:

En un día como los otros, un poco soleado, me encontrava fuera del salón con Jhonis y Lauri, en esas Marca Campesina (apodo) grito: Maria Melcocha (apodo), jaja fue muy gracioso, pero se escuchó un poco impedida (imposibilitada), Lauri y yo nos miramos y dijimos, como muy impedida la vieja.

Al otro dia, ivamos las tres o sea, Lauri Jhonis y yo a descanso, nos sentamos en la rotonda y habían 3 lechonas super guizas, terribles (mujeres a quienes se les considera muy feas) de $10^{\circ}$, jaja yo me puse a gritar como loca, y Lauri y yo gritábamos somos rockers woo (seguidoras del rock),

Instrumento No. 02: Producción de textos escritos (septiembre 05 de 2011)

Estas valoraciones o enunciados también expresan acontecimientos particulares de la vida de los hablantes, determinados por un lugar, un tiempo (contexto) $\mathrm{y}$, por su subjetividad, al conferir a las palabras un carácter lúdico o creativo. De ahí que la representación de la realidad constituya, para los hablantes, una forma de darse a conocer los oyentes y crear un significado propio para las palabras. 


\section{Conclusiones}

En relación con las representaciones sociales presentes en las expresiones de los jóvenes bogotanos, se encontró que éstas se asocian a ideas como la belleza, la fidelidad, la consideración de alguien como una persona de palabra, atrevida, de condición social baja o como una persona insignificante. Además, con la pertenencia o adhesión a un grupo social y con la legitimación de los comportamientos de otros a partir del reconocimiento de unos valores construidos social e históricamente como aquellos relacionados con la educación, la sensatez o los buenos modales. De ahí que el habla de los jóvenes bogotanos de cuenta de formas particulares de ver y significar el mundo.

En este sentido, podemos afirmar que el papel de las representaciones sociales de los jóvenes bogotanos, en la construcción y transformación de la cultura popular, supone procesos identitarios y de subjetivación que se expresan en el establecimiento de convenciones y comunidades lingüísticas, la conservación o transgresión de tradiciones y la generación de nuevos nexos entre lenguaje, sociedad y cultura.

El lenguaje se convierte en una forma de acción que consiste en la subversión de realidades existentes, en la creación de espacios simbólicos autoincluyentes y en la expresión de formas diversas que los jóvenes bogotanos tienen de representarse el mundo, su mundo. Tal es el caso del insulto, el eje alrededor del cual se articulan o construyen algunas de las representaciones sociales que los jóvenes bogotanos tienen acerca de la sociedad, los otros y ellos mismos, al asumirlo como un instrumento para la expresión de inconformismos y valoraciones negativas hacia quienes se dirigen. Además de reconocerle a éste una intencionalidad en el decir y en el actuar, a la que subyacen posibles modos de respuesta y resistencia.

Finalmente, se evidenció la interacción social como una posibilidad para la construcción de la cultura popular y la resignificación del habla de los jóvenes bogotanos en razón de las jerarquías, los juicios, los criterios éticos y estéticos y las relaciones semánticas contenidas en ésta.

\section{Referencias}

Abric, J. (1994) Prácticas y representaciones sociales. México: Ediciones Coyoacán.

Bajtin, M. (1997) La palabra en la vida y la palabra en la poesía Hacia una poética sociológica. Hacia una filosofía del acto ético. De los borradores y otros escritos (Traducción del ruso de Tatiana Bubnova). España: Editorial Anthropos.

Burke, P. (1996) Hablar y callar: funciones sociales del lenguaje a través de la historia (Traducción Alberto L. Bixio) Barcelona: Editorial Gedisa.

García, N, (1989). La crisis teórica en la investigación sobre cultura popular Homines, (6)

Fernández, A. (2002). Estereotipos y roles de género en el refranero popular. Barcelona: Editorial Anthropos.

Montes, J. (1998). El español hablado en Bogotá: Análisis previo de su estratificación social. Bogotá: Instituto Caro y Cuervo.

Mugny G., Carugati F., (1985) L 'intelligence au pluriel: les représentations sociales de I 'íntellígence et de son développement. Cousset: DelVal.

Zubieta, A., Blanco, O, Domine, M., Gómez, M., Imperatone, A., Montes, A. y Soriente, M. (2000). Cultura popular y cultura de masas. Conceptos, recorridos y polémicas. Granada. Editorial Paidós. 


\section{Anexo 1}

\begin{tabular}{|c|c|c|}
\hline CATEGORÍA & SUBCATEGORÍA & INDICADORES \\
\hline \multirow[b]{2}{*}{$\begin{array}{l}\text { Funciones de las representaciones } \\
\text { sociales }\end{array}$} & \multirow[b]{2}{*}{ Identidad } & $\begin{array}{l}\odot \text { Uso de palabras para expresar pertenencia } 0 \text { adhesión a } \\
\text { un grupo social }\end{array}$ \\
\hline & & $\begin{array}{l}\text { Pichurria: mala gente } \\
\text { Cachetoso: muy elegante, bueno } \\
\text { Caleto: callado } \\
\text { Calceto: faltón } \\
\text { Perro: amigo } \\
\text { Chirreto: chambón } \\
\text { Garbimba: tonto, bobo } \\
\text { Ñero: amigo } \\
\text { Re-ñero: gamín } \\
\text { Pex: parcero } \\
\text { Gremlin: enano } \\
\text { Chichón de piso: enano } \\
\text { Mi chancla: amigo }\end{array}$ \\
\hline CATEGORÍA & SUBCATEGORÍA & INDICADORES \\
\hline \multirow[b]{2}{*}{$\begin{array}{l}\text { Funciones de las } \\
\text { representaciones sociales }\end{array}$} & \multirow[b]{2}{*}{ Orientación } & $\begin{array}{l}\odot \text { Uso de palabras para expresar pertenencia } 0 \text { adhesión a } \\
\text { un grupo social }\end{array}$ \\
\hline & & $\begin{array}{l}\text { Ficty: exagerado } \\
\text { No me chimbee: no me engañe } \\
\text { Se armó la espantoza: pelea } \\
\text { Ruka: mujer } \\
\text { Todo fine: ir bien } \\
\text { Revika: hombre lindo } \\
\text { Cáspera: copión } \\
\text { Mona: muchacha } \\
\text { Visajoso: mal intencionado } \\
\text { Asare: estar asustado } \\
\text { Parlar: hablar } \\
\text { La montó: molestar demasiado } \\
\text { Al sospe: rapidito } \\
\text { Simio: expresión usada para ridiculizar a una persona } \\
\text { Guiza: mujer ordinaria } \\
\text { Sin bolas: modo de ofender o ridiculizar a alguien en broma o, en } \\
\text { una discusión } \\
\text { Túpale: hágalo, apúrele } \\
\text { Chimba: algo bacano } \\
\text { Áspero: bacano } \\
\text { N̂anga: dañado } \\
\text { Gochornea: cosa fuerte } \\
\text { Cagoretas: persona que mete la pata } \\
\text { Ratatulias: faltón, ladrón o persona que decepciona a otra } \\
\text { Zarnoso: persona extraña } \\
\text { Smigolom: persona fea que combina dos personajes de la película } \\
\text { El Señor de los Anillos } \\
\text { Gomoza: mujer creída } \\
\text { Me lo pela: no lo voy a hacer } \\
\text { Lámpara: persona incumplida, que roba costumbres o hace ridiculizar } \\
\text { a los demás }\end{array}$ \\
\hline
\end{tabular}




\begin{tabular}{|l|l|}
\hline \multicolumn{1}{|c|}{ Étıcos } & \multicolumn{1}{|c|}{ ESTÉTICOS } \\
\hline Bestia: persona inteligente y estudiosa & \\
"El mago"... norrea: el más maldadoso & \\
Antisemrif: persona infiel & \\
Pichipanguanorrea: incumplido, sin palabra & \\
Pirogorsofia: alzado, pasado de la raya & \\
Chirri: de barrio bajo (ñero) & \\
Asaltacunas: pedófilo & \\
Piltrofia: el caga parches & Longevos: viejos \\
Pifi: poca cosa & Roberto: mujer parecida a un hombre \\
Semrif: persona considerada fiel-firme & Burro: hombre moreno y narizón \\
Pelota: tonto, bobo & Cachetoso: muy elegante, bueno \\
La mamá de los pollitos: persona que se cree más que los demás o engreído \\
Poncio: tarado, bobo & Calceto: persona incumplida \\
Gil: lento & Chirreto: persona ordinaria \\
Ñanga: mala persona & Gremlin: enano \\
Ratatulias: faltón, ladrón o persona que decepciona a otra & Chichón de piso: enano \\
Gomoza: mujer creída & XD: cara sonriente \\
Ficty: persona exagerada/situación que carece de características reales \\
Lámpara: persona incumplida, que roba costumbres, que hace el oso o hace & Zarnoso: persona extraña \\
ridiculizar a los demás & Pushini: persona extraña \\
Caspero: copión & Smigolom: persona fea que combina dos personajes de la película \\
Visajoso: lambón & el Señor de los Anillos \\
Guiza: mujer ordinaria & Simio: expresión utilizada para ridiculizar a una persona \\
Gomoza: mujer creída & Taguán: mujer bonita \\
Severo: impactante/de agrado & \\
Zunga: mujer fácil & \\
Foxxic: mujer fácil & \\
Coiro: tonto & \\
Boby: tonto & \\
Suripanta: mujer de todos & \\
Guaso: genial & \\
Fumado: perdido del tema & \\
Farándula: mujer tonta & \\
Farandulera: persona a quien le gusta llamar la atención & \\
\hline
\end{tabular}




\section{Anexo 2}

\begin{tabular}{|c|c|c|}
\hline CATEGORÍA & SUBCATEGORÍA & INDICADORES \\
\hline \multirow[b]{2}{*}{ Cultura popular } & \multirow[b]{2}{*}{ Jerarquías } & $\odot \quad$ Uso de palabras para establecer diferenciación social \\
\hline & & $\begin{array}{l}\text { Chirri: de barrio bajo (ñero) } \\
\text { Pifi: poca cosa } \\
\text { Roberto: mujer parecida a un hombre } \\
\text { Burro: hombre moreno y narizón } \\
\text { Pelota: tonto, bobo } \\
\text { Chirreto: ordinario } \\
\text { Garbimba: tonto, bobo } \\
\text { Gremlin: enano } \\
\text { Chichón de piso: enano } \\
\text { Baboso: bruto } \\
\text { Rata: ladrón } \\
\text { Guiso: persona ordinaria } \\
\text { Coica: mujer bruta } \\
\text { Poncio: tarado, bobo } \\
\text { Gil: lento } \\
\text { Zarnoso: persona extraña } \\
\text { Smigolom: persona fea que combina dos personajes de la película El Señor de los Anillos } \\
\text { Guiza: mujer ordinaria } \\
\text { Zunga: mujer fácil } \\
\text { Foxxic: zorrita } \\
\text { Coiro: tonto } \\
\text { Boby: tonto } \\
\text { Cula: estúpida }\end{array}$ \\
\hline
\end{tabular}

THE AUTHOR

YINETH RIAÑO BAYONA, M.A in Interdisciplinary Social Research and holds a degree in Humanities and Spanish from Universidad Distrital Francisco José de Caldas. She has been a high-school vocational Spanish Language teacher. She teaches Spanish Language in Colegio Colsubsidio Norte. 